\title{
Integration of Remote Sensing and Ground-Based Non-Destructive Methods in Transport Infrastructure Monitoring: Advances, Challenges and Perspectives
}

\author{
Fabio Tosti \\ School of Computing and Engineering \\ University of West London (UWL) \\ St Mary's Road, Ealing, London, UK \\ Fabio.Tosti@uwl.ac.uk \\ Andrea Benedetto \\ Department of Engineering \\ Roma Tre University \\ Via Vito Volterra 62, Rome, Italy \\ andrea.benedetto@uniroma3.it
}

\author{
Valerio Gagliardi \\ Department of Engineering \\ Roma Tre University \\ Via Vito Volterra 62, Rome, Italy \\ valerio.gagliardi@uniroma3.it \\ Sue Threader \\ The Rochester Bridge Trust \\ St Andrew's House, The Precinct, \\ Rochester, UK \\ bridgeclerk@rbt.org.uk
}

\author{
Luca Bianchini Ciampoli \\ Department of Engineering \\ Roma Tre University \\ Via Vito Volterra 62, Rome, Italy \\ luca.bianchiniciampoli@uniroma3.it \\ Amir M. Alani \\ School of Computing and Engineering \\ University of West London (UWL) \\ St Mary's Road, Ealing, London, UK \\ Amir.Alani@uwl.ac.uk
}

\begin{abstract}
High temporal frequency monitoring of transport infrastructures is crucial for implementing effective maintenance prioritisation strategies and prevent major failures. To this extent, ground-based non-destructive testing (NDT) methods have been successfully applied for decades, reaching very high standards of data quality and accuracy. However, routine and systematic campaigns are required over relatively long inspection times for data collection and implementation into reliable infrastructure management systems (IMSs). On the other hand, satellite remote sensing techniques, such as the Multi-Temporal Interferometric Synthetic Aperture Radar (MT-InSAR) method, have proven effective in monitoring ground displacements of transport infrastructures (roads, railways and airfields), with a much higher temporal frequency of investigation and wider inspection catchment areas. Nevertheless, the integration of information from i) satellite remote sensing and ii) ground-based NDT methods is still an area to be explored in civil engineering. Within this framework, this paper aims to review significant stand-alone applications in these two areas of technology for transport infrastructure monitoring. Furthermore, recent advances, main challenges and future perspectives arising from their integration are discussed. Contents of this paper are organised within the context of an invited keynote talk given at the 2021 IEEE Asia-Pacific Conference on Geoscience, Electronics and Remote Sensing (AGERS - 2021).
\end{abstract}

Keywords-satellite remote sensing, ground-based nondestructive testing (NDT) methods, transport infrastructure monitoring, Multi-Temporal Interferometric Synthetic Aperture Radar (MT-InSAR), data and systems integration

\section{INTRODUCTION}

Continuous monitoring of transport infrastructures, such as railways, roads and bridges, is a priority for asset owners and administrators to ensure structural stability, operational safety and preventing damage and deterioration - leading to expensive rehabilitation, or failures and collapses [1]. Currently, several ground-based non-destructive testing (NDT) technologies and sensors are available for subsidence monitoring and displacement mapping. Amongst others, accelerometers [2], strain gauges [3], Global Position System (GPS) [4], levelling [5], Ground Penetrating Radar (GPR), Infrared Thermography (IRT) [6-10] and terrestrial Synthetic
Aperture Radar (SAR) Interferometry [11], are acknowledged as effective technologies for infrastructure monitoring.

However, on-site surveys are costly and challenging to implement at the network level, causing economic and administrative budget constraints. To overcome this limitation, several advanced satellite-based remote sensing techniques, i.e., the Persistent Scatterers Interferometry (PSI), among which the PS-InSAR [12] and the Small BAseline Subset (SBAS) [13], have gained momentum in the past two decades for the monitoring of transport assets and the investigation of the surrounding environment.

In the last few years, several successful applications have proven the viability of using satellite-based remote sensing techniques for infrastructure monitoring purposes [14]. In addition to this, a wide land coverage and the possibility to collect data with a high temporal frequency have encouraged the use of this technology in combination with other monitoring techniques. In this context, the concept of data integration stands as a future challenge in research [15]. To elaborate, new studies have recently emerged with the aim to define novel methods for integration of information collected with different technologies, involving datasets of different spatial and temporal resolutions. A main advantage of these integrated approaches is in the provision of additional levels of information, which are not available from a stand-alone use of individual technologies [16]. This paper is organised as follows: the Introduction given in Section I is followed by an overview of significant stand-alone applications of satellite remote sensing and ground-based NDT methods (Section II). Section III reports recent studies into the combined application and data integration between the above two methods in transport infrastructure monitoring (roads, railways, airfields and historical bridges). Conclusions, challenges and future perspectives are discussed in Section IV.

\section{StAnd-Alone SATEllite AND GROUND-BASED TECHNOLOGY APPLICATIONS IN TRANSPORT INFRASTRUCTURE MONITORING}

\section{A. Satellite Remote Sensing Techniques}

In the last 20 years, several processing techniques have been proposed for displacement mapping from SAR imaging 
and, amongst the most acknowledged, is the Permanent Scatterers InSAR (PSI), i.e., a multi-temporal SAR approach. [12]. The working framework of this technique is based on a statistical analysis of the signals emitted by the on-satellite sensor and back-scattered by a network of coherent targets on the ground, i.e., the Permanent Scatterers (PSs). This approach allows to estimate the displacements occurred across different acquisitions by a separation between the phase shift - related to the ground motions - and the phase components due to the atmosphere, the topography and the signal noise contributions [12,17]. An advantage of this technique is the relatively lighter data-processing required for the assessment of displacements and the detection of critical areas, as opposed to the higher computational load needed with other approaches.

In the last decade, the PSI technique has proven effective in land monitoring applications, such as landslide surveillance $[18,19]$, pre- and post-seismic evaluations $[20,21]$ and urban subsidence detection [22,23]. With regard to the monitoring of transport infrastructures, recent research on emerging applications of the PSI technique is summarised below:

- Pavement distress assessment. Linear infrastructures in rural environment contexts are amongst the most reflective targets in terms of SAR transmissions, triggering the formation of many PSs for a PSI analysis. This implies that the PSI technique can be inherently effective in the monitoring of major pavement distresses (e.g., rutting, deformations and settlements), e.g., in highway [24] and airport infrastructures [25].

- Bridge monitoring. It is known that vertical and horizontal displacements at the piers of bridges may seriously compromise their structural stability. This occurrence is generally related to geodynamic (e.g., the sliding of the slope) or geotechnical issues (e.g., oedometric subsidence at the piles). The application of the PSI technique and, in general, the SAR-based processing techniques, was successful with the evaluation of three major features in bridge monitoring. To elaborate, the linear deformation trend, the height of the structure over terrain, and the thermal expansion were proven to create variations in the SAR phase [26,27].

- Assessment of tunnelling-induced subsidence. The effects of tunnel excavations on the geotechnical stability of contextual areas are well-known. Overall, formation of vertical settlements is first observed at the tunnel construction stage, followed by an increased stability of the concerning area compared to the surrounding, once the structure is built. An accurate assessment of these two major stages is crucial for predicting any potential future subsidence expected on nearby buildings and infrastructures. To this purpose, successful research on the application of the PSI technique has been reported [28,29]. In particular, multi-temporal SAR analyses have allowed to monitor the entire construction process, and predict the stability of the investigated area to ground settlements.

Research in stand-alone use of the PSI technique for transport infrastructure monitoring - sorted by infrastructure type - is reported in Table I.
TABLE I. PSI APPLICATIONS (STAND-ALONE USE OF SATELLITE TECHNOLOGY) FOR TRANSPORT INFRASTRUCTURE MONITORING

\begin{tabular}{|c|c|}
\hline Infrastructure Type & References \\
\hline Highways and tunnels & {$[24,28,29]$} \\
\hline Railways & {$[30-32]$} \\
\hline Airfields & {$[25,33]$} \\
\hline $\begin{array}{c}\text { Viaducts and Historical } \\
\text { bridges }\end{array}$ & {$[34-38]$} \\
\hline
\end{tabular}

\section{B. Ground-Based Non-Destructive Testing Methods}

The use of ground-based NDT methods for the assessment of transport infrastructures has tremendously spread in the last decades. Several applications and case studies carried out by means of indirect non-invasive technologies have been successfully presented in the literature, proving their contribution to enhance the productivity of asset monitoring activities. To this effect, research advances on the use of NDT methods have been reported in many areas of transportation and pavement engineering $[39,40]$, including applications on highways [41,42], railways [43,44] and airfields [45,46].

A wide availability of multi-source, multi-scale and multitemporal information on infrastructure conditions, as well as the advancement of hardware and software technologies, have contributed to create new opportunities for further expansion in the application of NDT methods. The information produced lends itself to be incorporated into existing infrastructure management models $[47,48]$. Relying on established design and verification guides $[49,50]$, the rationale is to exploit the higher productivity of the ground-based NDT techniques and use the outcomes for incorporation into existing models for network infrastructure asset management.

Within this context, it is observed that compliance to increasingly challenging budget and environmental goals is moving the research focus towards the development of more advanced, rapid and reliable NDT methods for pavement assessment purposes. Efforts are being spent on the provision of continuous and faster measurements to replace existing non-destructive technologies based on discrete methods of data collection [51]. This is undoubtedly related to the higher testing frequency requirements for certain types of infrastructure (e.g., railways and airfields) as well as to the inherent configuration of linear transport infrastructures, where stop-and-go operations and partial or full-service interruption (e.g., lane closures) can dramatically affect the infrastructure functionality and operability. New paradigms based on the use of non-destructive technologies have been introduced $[44,52,53]$ and other existing NDTs have been integrated in an attempt to sort out resolution and data collection time limitations [40,51], and exploit their full potential.

\section{Satellite Remote Sensing AND Ground-Based Non- DESTRUCTIVE TESTING METHODS IN TRANSPORT INFRASTRUCTURE MONITORING: COMBINED APPLICATIONS AND DATA INTEGRATION STUDIES}

Based on the discussed research focus about the integration between satellite remote sensing and groundbased NDT methods, the following sections report an overview of research and applications sorted by infrastructure type, i.e., roads, railways, airfields, bridges and tunnels. 


\section{A. Roads}

Roads are excellent targets for InSAR monitoring. Research has confirmed a very high suitability of this technique in detecting displacements for highways, motorways and road intersections, reaching a millimetre accuracy of measurements. However, these applications have proven that, despite of a large availability of PSs in urban areas, it could be difficult to allocate the information to the concerning structural element, especially in case mediumresolution SAR data (e.g., C-band) are utilised.

This issue has been overcome by using last-generation SAR data acquired in X-band [54], where a pixel resolution up to $1 \mathrm{~m}$ can be reached. This is the case of the Spotlight images from the COSMO-SkyMed mission of the Italian Space Agency (ASI), with a resolution up to 0.5 and $1 \mathrm{~m}$ (i.e., for the Spotlight $a, b)$, and the Stripmap SAR images with a resolution of $3 \times 3 \mathrm{~m}$.

In this context, an experimental activity was conducted over the Aylesford area, in Kent, UK, where a novel "integrated" holistic health monitoring approach - including the Ground Penetrating Radar (GPR) and the Interferometric Synthetic Aperture Radar (InSAR) techniques - is proposed. The processing of COSMO-SkyMed Stripmap products demonstrated a high-suitability of the PSI technique for application to roads [55].

More specifically, the analysis allowed to identify several coherent PS points across various roads, bridges and buildings in the investigated area.

The analysis was completed by GPR investigations (Fig. 2) providing structural details of the subsurface (e.g., the pavement structure of a river bridge) $[55,56]$. The presented approach allowed to have a clear mapping of the main subsurface structural features (GPR) in addition to long-term information about the behaviour of structures and infrastructures involved in this investigation (InSAR).

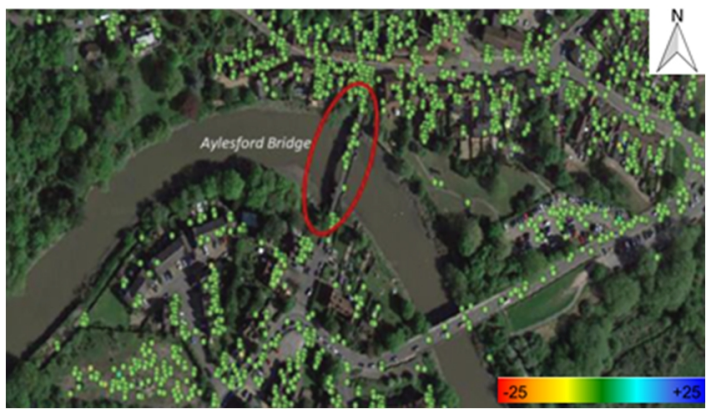

Fig. 1. PSI application: a) PSI results over the Area of Interest displayed in relation to the average trend of velocity (green points are stable scatterers).

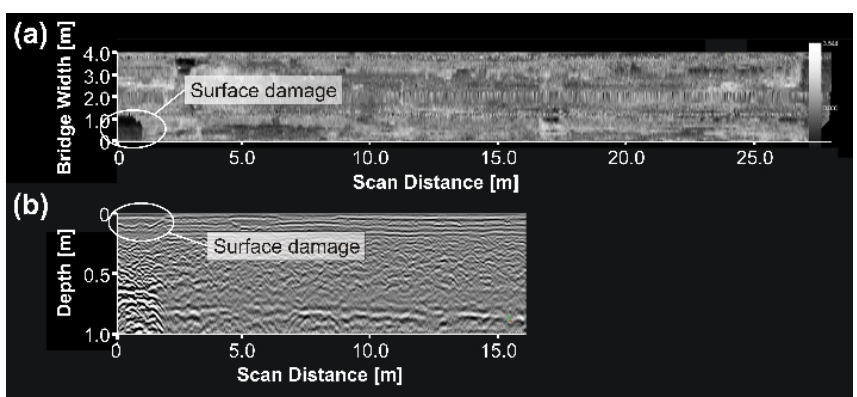

Fig. 2. Surface reinstatement identified on the Aylesford Bridge pavement a) a C-scan (5 cm deep) and b) a B-scan view [56].

\section{B. Railways}

Similar to roads, railways are excellent scatterers for InSAR analyses. Detected ground displacements are caused by a variety of factors, which may be due in turn to different sources of structural damage, of which most are in the subsurface. To this extent, the GPR technology lends itself to be incorporated into InSAR investigations of railway infrastructures. Bianchini et al. [14] investigated a 10km-long railway section using InSAR and GPR methods. The PSI analysis allowed to identify critical PSs, affected by subsidence, in the first kilometre of the railway area investigated (Fig. 3). Both medium-resolution (C-band) and high-resolution (X-band) satellite data were used for the purpose.

Furthermore, an in-depth analysis of the GPR radargrams allowed to associate this section with several areas affected by a high attenuation of the signal (Fig. 4). To elaborate, the authors observed weak reflections at the interface between the sub-ballast layer and the subgrade, showing discontinuous patterns in the radargrams. This was likely related to fouling and clay intrusion at the ballast foundation level.

With similar scopes and methods, Tosti et al. [57] monitored a railway section affected by subsidence. A clear matching was found between areas with displacements and areas affected by potential fouling effects through InSAR and GPR techniques, respectively. Sections with high attenuation of the GPR signal at the foundation level (i.e., the interface between the sub-ballast layer and the subgrade) were found to match with sections where highest subsidence was observed through InSAR analyses.

In general, both the studies have proven the effectiveness of integrating satellite and ground-based information for structural health monitoring of railways.
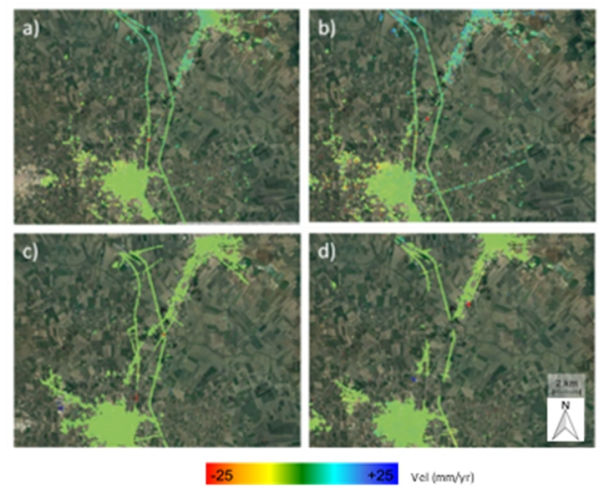

Fig. 3 Application of the PSI technique to Sentinel datasets in a) ascending and b) descending geometries, and COSMO-SkyMed data in c) ascending and d) descending acquisition geometries [14].
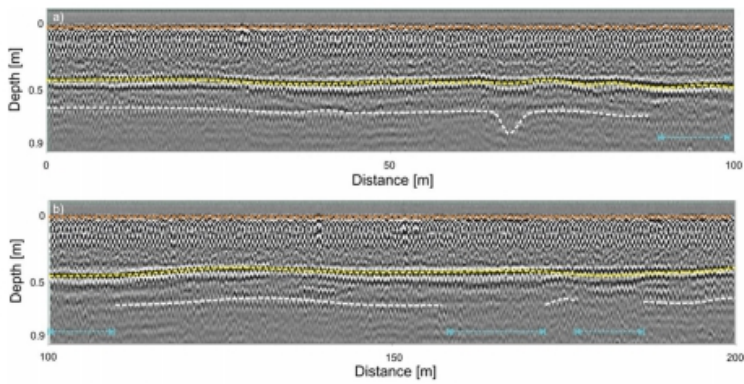

Fig. 4 GPR data collected at the critical section showing subsidence from the InSAR analyses. Discontinuities at the sub-ballast-subgrade interface at sections: a) $0 \div 100 \mathrm{~m}$ and b) $100 \div 200 \mathrm{~m} \mathrm{[14]}$. 
D'Amico et al. [58] used InSAR and GPR technologies for monitoring the rail-abutment transition area in a railway truss bridge. To elaborate, GPR was utilised to collect subsurface structural details of the railway superstructure/substructure including ordinary rail sections before and after the bridge section. Outcomes from the GPR surveys excluded any potential construction-related issue. A section of the railway at one of the approaches was found to be affected by a high reflectivity of the signal at the ballast foundation level. This section matched with an area of subsidence clearly identified by the PS-InSAR analysis carried out over the entire railway section investigated in this study. By combining the information from GPR and InSAR, the authors concluded that unproper compaction of the ballasted layers could have been the main cause of differential displacements at the railabutment transition area.

\section{Airfields}

Amongst the most recent applications conducted on airports, Gagliardi et al. [59] presented a study carried out on Runway n. 3 at the Da Vinci International Airport (Fiumicino Airport) located in Fiumicino, Rome, Italy. Two different SAR datasets were processed including i) Sentinel 1 (C-band) data in both the acquisition geometries (i.e., ascending and descending), and ii) COSMO-SkyMed (X-band) data. Datasets covered a time frame from April 2017 to December 2019. Furthermore, measurements were also collected on the runway using the ground-based topographic levelling technique. The aim of this study was to test the viability of using medium-resolution SAR interferometry data in monitoring ground displacements on runways at the millimetre scale.

To this purpose, a geostatistical analysis was developed to i) study the statistical variability of the datasets, ii) interpolate the Sentinel-1 data through an Ordinary Kriging (OK) method and iii) compare the interpolated displacements to the values collected on-site by topographic levelling. Fig. 5 shows major outcomes from the use of ground-based topographic levelling data (Fig. 5a) and satellite remote sensing data (medium (Fig. 5b) and high-resolution (Fig. 5c)) on the runway.

A comparison between the PSI outcomes from the Sentinel-1A SAR data, interpolated through OK, and the ground-truth topographic levelling data demonstrated a relatively high accuracy of the medium-resolution data. This is proven by the high values of the correlation coefficient ( $r=$ $0.94)$, the multiple $R$-squared coefficient $\left(R^{2}=0.88\right)$ and the Slope value (0.96), as reported in Fig. 6.
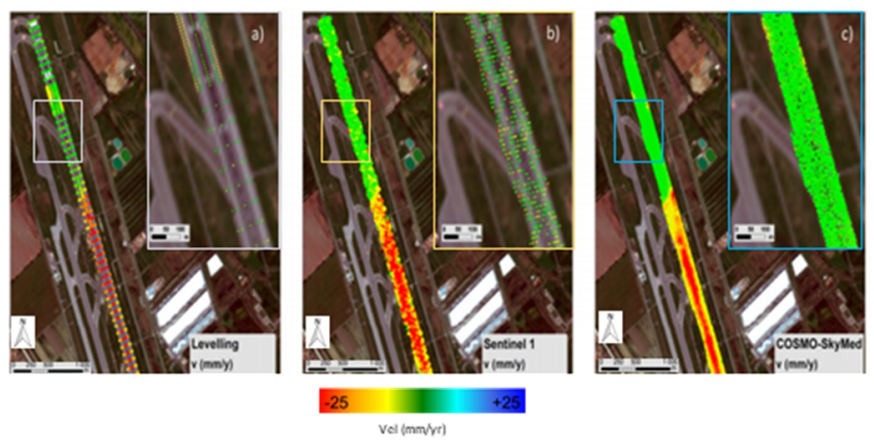

Fig. 5. Classed post maps of the ground displacements recorded by a) Levelling; b) Sentinel-1; c) COSMO-SkyMed. The basemap is a satellite orthophoto from the Sentinel 2 sensor (ESA-Copernicus). edited from [59].

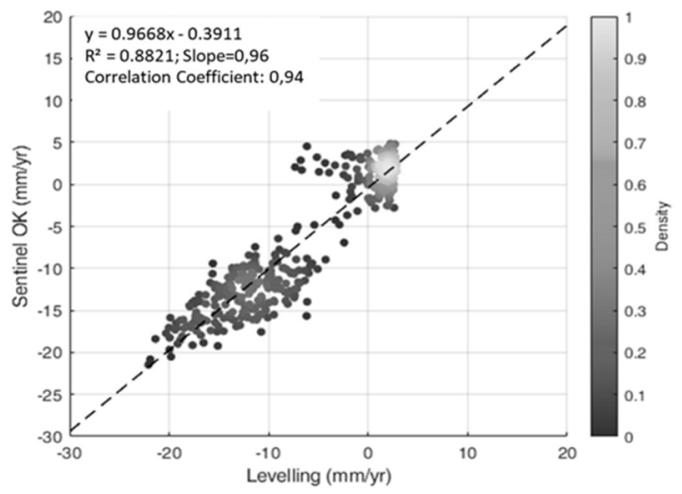

Fig. 6. Scatter plot of the interpolated Sentinel-1 deformations compared to the levelling deformations, with regression line and related fitting diagnostics [59].

In [60], an InSAR investigation was conducted into the differential settlements observed on one of the runways at the Fiumicino International Airport in Rome. Several COSMOSkyMed X-band SAR images were processed by means of a PS-InSAR approach, highlighting the presence of vertical displacements. These were compared to the outputs from a dense levelling campaign conducted over four years' time. The limited errors confirmed that PS-InSAR analyses of high frequency images are very effective in reconstructing vertical deformations in airfield runways. In [61], a novel geostatistical approach was developed to ease the postprocessing of large datasets of PSs resulting from the application of the PSI algorithms over an area of interest. The approach aims at correcting the component of the displacement collected from the acquisition geometry of the sensor (i.e., ascending and descending), and to increase the accuracy of measurements.

As a prospective development of this research, the authors propose an integration with the GPR technology, to incorporate information about the subsurface of the runway and enhance the detection and the interpretation of relevant sources of structural damage.

\section{Historical Bridges}

In the last few years, several research has been presented about the monitoring of bridges with satellite remote sensing techniques and the investigation of the surrounding environment. Amongst these, the PSI technique is gaining momentum due to the provision of very dense and routinely updated datasets, and the possibility to reconstruct the historical time-series of displacements using SAR archive images [34-38, 61,62]. Parallel to this, literature is showing a progressive increase of research regarding the use of groundbased NDTs, especially GPR, as fundamental investigation tools in bridge diagnostics [63]. Despite the above methodologies can collect reliable information, a fully comprehensive and routine diagnostics of the bridge conditions cannot be pursued, if these techniques are utilised individually. To this end, the integration of multi-source, multi-temporal and multi-resolution datasets represents a future challenge and an area of further research development.

Amongst the most recent applications, a great interest has been paid to the monitoring of historical bridges and cultural heritage sites with satellite remote sensing methods. Results achieved demonstrated the effectiveness of these techniques, paving the way for further integration with ground-based NDT methods. 
More specifically, in [38] and [64] a PSI analysis was developed to monitor and detect potential structural displacements of the Rochester Bridge, located in Rochester, UK, for use and integration with field inspections in future studies. With this being said, it is worthy to recall that the provision of detailed measurements is a key factor in the monitoring of critical structures, such as bridges. However, the provision of high-resolution archive datasets must be regarded as an exceptional source of time-series information, that cannot be collected with any other on-site equipment currently available.

Within this context, research in [64] aims to demonstrate the viability of using X-band SAR imagery for effective monitoring of historical bridges. To this purpose, a dataset of $\mathrm{X}$-band data, acquired in the framework of the COSMOSkyMed mission by ASI, was collected and processed for the monitoring of the Rochester Bridge, UK. A clustering technique based on the data semantic of the PSs observed in the bridge area allowed to allocate relevant information to individual structural elements of the bridge, such as piers and arcs. Overall, a reference range between maximum and minimum displacements observed in this study was in the order of a few millimetres. Fig. 7 shows that no critical areas nor significant subsidence were detected for the relevant PS data clusters. On the other hand, an average down-lifting deformation trend of around $5 \mathrm{~mm}$ was observed to have occurred across the three years of observation on the selected element.

\section{Conclusions, Challenges and Future Perspectives}

This paper reviews new developments and applications of satellite remote sensing and ground-based non-destructive testing (NDT) methods in transport infrastructure monitoring. A special focus is given to the integration between these two areas of technology and their most recent applications in the field. Overall, it is observed that excellent progress has been made in terms of the high standards of data quality and the accuracy that have been reached in both these areas of technology. However, a stand-alone use of these technologies is naturally constrained by physical (e.g., limitations in terms of nominal data resolutions of the equipment) and productivity (e.g., limitations in terms of land coverage or data acquisition pace) factors, which poses an issue on how to improve upon limitations and enhance their applicability in the sector.

a)

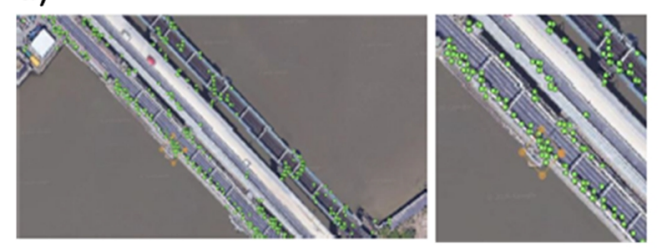

b)

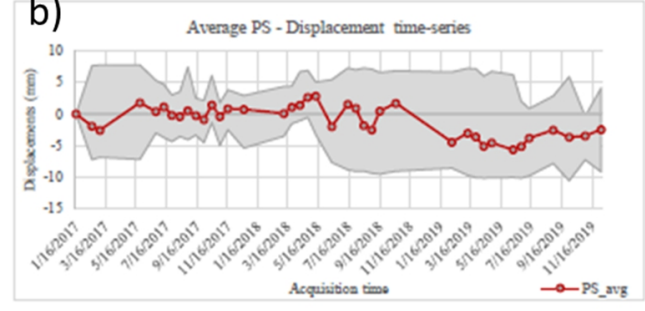

Fig. 7. a) PS cluster selection: definition of an area sized $10 \times 10 \mathrm{~m}$ followed by PSs allocation to relevant bridge structural elements; $b$ ) average PS displacement time-series (2017-2019) and variation domain of the PS deformations [64]
The concept of "technology and data integration" is one of the options to answer this fundamental research question. To this extent, it has emerged that new research has been carried out on combined applications and data integration studies involving satellite remote sensing and ground-based NDT methods across all transport infrastructure modes (highways, railways and airfields). Furthermore, historical bridges have been a focus of recent research involving these two areas of technology.

At present, Ground Penetrating Radar (GPR) stands as a preferred technology for integration with Interferometric Synthetic Aperture Radar (InSAR) techniques. This is due to the possibility of exploring subsurface features and provide a more comprehensive diagnostics of the causes of ground displacements.

On the other hand, the concept of integration triggers some challenges, that can be summarised as follows:

- existing Permanent Scatterer (PS) approaches have proven to work effectively. However, there are limitations in terms of target accuracy that can limit their applicability in certain areas of transport engineering;

- the variety of techniques available as well as the difference in the physics and working principles of the inspection equipment make it complex to identify the actual gaps in the quality and type of information provided. A clear matching between these gaps and the actual needs in transport infrastructure monitoring is still a point of debate;

- although several NDT methods have gained official recognition as fundamental tools for integration in Infrastructure Management Systems (IMSs), it is observed that satellite remote sensing techniques have not yet entered that stage. At present, this condition could stand as a limitation for any potential development based on the integration between these two areas of technology.

The above challenges could be also looked at as prospective points of research development, as follows:

- to investigate more deeply into the development of new potential SAR analysis methods using innovative Permanent Scatterer (PS) approaches (e.g., Non-linear displacement models, integrated PSI-SBAS approaches and Distribuited Scatterers (DS) methods);

- to orient research towards filling the gap given by a stand-alone use of individual technologies, promoting their integration. A comprehensive theoretical and practical knowledge of these techniques as well as of the actual needs from several transport infrastructure sectors are essential to identify the right direction. It is the authors' opinion that the implementation of advanced Machine Learning and Deep Neural Networks (DNN) algorithms can support this process;

- to invest into the development of more advanced Infrastructure Management Systems (IMSs) with capacity and resources to integrate satellite remote sensing and ground-based technologies at the network level. 


\section{ACKNOWLEDGMENTS}

This paper reports research supported by the Italian Ministry of Education, University and Research under the National Project "EXTRA TN", PRIN 2017, Prot. 20179BP4SM. Authors would also like to acknowledge and thank the Rochester Bridge Trust for facilitating and supporting research discussed in this paper.

\section{REFERENCES}

[1] Chang P.C., Flatau A. \& Liu S. C. "Review Paper: Health Monitoring of Civil Infrastructure". Structural Health Monitoring, 2(3), 257-267. 2003.

[2] Kongyang C., Mingming L., Xiaopeng F., Mingming W. and Wu J., "Road condition monitoring using on-board Three-axis Accelerometer and GPS Sensor," 6th International ICST Conference on Communications and Networking in China, Harbin, 2011

[3] Olund J., \& DeWolf J., "Passive Structural Health Monitoring of Connecticut's Bridge Infrastructure". Journal of Infrastructure Systems, 13(4), 330-339. 2007.

[4] Mossop A., Segall P., "Subsidence at The Geysers Geothermal Field, N. California from a comparison of GPS and leveling surveys". Geophys. Res. Lett., 24, 1839-1842, 1997

[5] Sato H.P., Abe K., Ootaki O., "GPS-measured land subsidence in Ojiya City, Niigata Prefecture, Japan”. Eng. Geol., 67, 379-390, 2003.

[6] Saarenketo T. \& Scullion T., (2000). "Road evaluation with ground penetrating radar". Journal of Applied Geophysics, 43(2-4), 119-138.

[7] Lagüela S., Solla M., Puente I., \& Prego F. J., (2018). “Joint use of GPR, IRT and TLS techniques for the integral damage detection in paving". Construction and Building Materials, 174, 749-760.

[8] Bianchini Ciampoli L., Artagan S. S., Tosti F., Gagliardi V., Alani A. M. and Benedetto A., "A comparative investigation of the effects of concrete sleepers on the GPR signal for the assessment of railway ballast", 17th International Conference on Ground Penetrating Radar (GPR), Rapperswil, pp. 1-4, doi: 10.1109/ICGPR.2018.8441588, 2018.

[9] Benedetto, F. Tosti, L. B. Ciampoli, and F. D'Amico, "GPR applications across engineering and geosciences disciplines in Italy: A review," IEEE J. Sel. Topics Appl. Earth Obs. Remote Sens., vol. 9, no. 7, pp. 2952-2965, Jul. 2016.

[10] Tosti, F. and Benedetto, A. (2012) "Pavement Pumping Prediction Using Ground Penetrating Radar. Procedia Social and Behavioral Sciences", 53 , 1054.https://doi.org/10.1016/j.sbspro.2012.09.954

[11] Monserrat, O., Crosetto, M., \& Luzi, G. (2014). A review of groundbased SAR interferometry for deformation measurement. ISPRS Journal of Photogrammetry and Remote Sensing, 93, 40-48. doi:10.1016/j.isprsjprs.2014.04.0

[12] Ferretti A., Prati C., Rocca F., "Permanent scatters in SAR interferometry". IEEE Trans Geosci Remote Sens 39(1):8-20, 2001. https ://doi.org/10.1109/36.898661

[13] Lanari R., Mora O., Manunta M., Mallorqui J.J., Berardino P., Sansosti E. "A small baseline approach for investigating deformation on full resolution differential SAR interferograms". IEEE Trans. Geosci. Remote Sens. 42, 1377-1386, 2004.

[14] Bianchini Ciampoli L., Gagliardi V., Clementini C., et al. "Transport Infrastructure Monitoring by InSAR and GPR Data Fusion". Surv Geophys 41, 371-394. 2020. https://doi.org/10.1007/s10712-01909563-7

[15] Tosti, F.; Benedetto, A.; Ciampoli, L.B.; D'Amico, F.; Plati, C.; Loizos, A. Guest Editorial: Data Fusion, integration and advances of non-destructive testing methods in civil and environmental engineering. NDT E Int. 2020, 115, 102286.

[16] Tosti, F.; Alani, A.M.; Benedetto, A.; Loizos, A.; Soldovieri, F. Guest Editorial: Recent Advances in Non-destructive Testing Methods. Surv. Geophys.2020,41, 365-369.

[17] Ferretti A., Prati C., Rocca F. "Nonlinear subsidence rate estimation using permanent scatterers in differential SAR interferometry". IEEE Trans Geosci Remote Sens 38(5):2202-2212, 2000.

[18] Rosi, A., Tofani, V., Tanteri, L. et al. The new landslide inventory of Tuscany (Italy) updated with PS-InSAR: geomorphological features and landslide distribution. Landslides 15, 5-19 (2018). https://doi.org/10.1007/s10346-017-0861-4
[19] Colesanti, C., \& Wasowski, J. (2006). Investigating landslides with space-borne Synthetic Aperture Radar (SAR) interferometry. Engineering $\quad$ Geology, 173-199), doi:10.1016/j.enggeo.2006.09.013

[20] Moro, M., Saroli, M., Stramondo, S. et al. New insights into earthquake precursors from InSAR. Sci Rep 7, 12035 (2017). https://doi.org/10.1038/s41598-017-12058-3

[21] Atzori, S., Hunstad, I., Chini, M., Salvi, S., Tolomei, C., Bignami, C., Stramondo S., Trasatti E., Antonioli A. and Boschi, E. (2009). Finite fault inversion of DInSAR coseismic displacement of the 2009 L'Aquila earthquake (central Italy). Geophysical Research Letters, 36(15), n/a-n/a. doi:10.1029/2009g1039293

[22] Stramondo, S., Bozzano, F., Marra, F., Wegmuller, U., Cinti, F. R., Moro, M., \& Saroli, M. (2008). Subsidence induced by urbanisation in the city of Rome detected by advanced InSAR technique and geotechnical investigations. Remote Sensing of Environment, 112(6), 3160-3172. doi:10.1016/j.rse.2008.03.008

[23] Chaussard, E., Amelung, F., Abidin, H., \& Hong, S.-H. (2013). Sinking cities in Indonesia: ALOS PALSAR detects rapid subsidence due to groundwater and gas extraction. Remote Sensing of Environment, 128, 150-161. doi:10.1016/j.rse.2012.10.015

[24] Ozden, A., Faghri, A., Li, M., Tabrizi, K., Evaluation of Synthetic Aperture Radar Satellite Remote Sensing for Pavement and Infrastructure Monitoring, Procedia Engineering, 145, 752-759, 2017

[25] Marshall, C., Large, D.J., Athab, A., Evers, S.L., Sowter, A., Marsh, S., Sjögersten, S., Monitoring tropical peat related settlement using ISBAS InSAR, Kuala Lumpur International Airport (KLIA), Engineering Geology, 244, 3, 57-65, 2018.

[26] Lazecky, M., Hlavacova, I., Bakon, M., Sousa, J. J., Perissin, D., Patricio, G., Bridge Displacements Monitoring Using Space-Borne XBand SAR Interferometry, in IEEE Journal of Selected Topics in Applied Earth Observations and Remote Sensing, 10, 1, 205-210, 2017

[27] Zhao, J., Wu, J., Ding, X., Wang, M., Elevation extraction and deformation monitoring by multitemporal InSAR of Lupu Bridge in Shanghai, Remote Sensing, 9, 9, 897, 2017

[28] Milillo, P., Giardina, G., DeJong, M.J., Perissin, D., Milillo, G., Multitemporal InSAR structural damage assessment: The London crossrail case study, Remote Sensing, 10, 2, 287, 2018

[29] Barla G. et al., "InSAR monitoring of tunnel induced ground movements. Geomechanik und Tunnelbau" 9(1):15-22, 2016.

[30] Perissin, D., Wang, Z., Lin, H., Shanghai subway tunnels and highways monitoring through Cosmo-SkyMed Persistent Scatterers, ISPRS Journal of Photogrammetry and Remote Sensing, 73, 58-67, 2012

[31] Chang L., Dollevoet R. P., \& Hanssen R. F., "Nationwide Railway Monitoring Using Satellite SAR Interferometry". IEEE Journal of Selected Topics in Applied Earth Observations and Remote Sensing, 10(2),596-604. 2017.

[32] Qin X., Liao M., Zhang L., \& Yang M.," Structural Health and Stability Assessment of High-Speed Railways via Thermal Dilation Mapping with Time-Series InSAR Analysis". IEEE Journal of Selected Topics in Applied Earth Observations and Remote Sensing, 10(6), 2999-3010. 2017.

[33] Gao, M.; Gong, H.; Chen, B.; Zhou, C.; Chen, W.; Liang, Y.; Shi, M.; $\mathrm{Si}$, Y. InSAR time-series investigation of long-term ground displacement at Beijing Capital International Airport, China. Tectonophysics 2016, 691, 271-281.

[34] Gagliardi V., Benedetto A., Bianchini Ciampoli L., D'Amico F., Alani A. M., Tosti F. "Health monitoring approach for transport infrastructure and bridges by satellite remote sensing Persistent Scatterers Interferometry (PSI)", Proc. SPIE 11534. 2020. https://doi.org/10.1117/12.2572395

[35] M. Lazecky, I. Hlavacova, M. Bakon, J. J. Sousa, D. Perissin and G. Patricio, "Bridge Displacements Monitoring Using Space-Borne XBand SAR Interferometry," in IEEE Journal of Selected Topics in Applied Earth Observations and Remote Sensing, vol. 10, no. 1, pp. 205-210, Jan. 2017, doi: 10.1109/JSTARS.2016.2587778.

[36] Gagliardi V., Bianchini Ciampoli L., D'Amico F., Alani A. M., Tosti F., Battagliere M. L., Benedetto A., "Bridge monitoring and assessment by high-resolution satellite remote sensing technologies", Proc. SPIE 11525, SPIE Future Sensing Technologies. 2020. doi: $10.1117 / 12.2579700$

[37] Jung J., Kim D-J, Palanisamy Vadivel SK, Yun S-H. "Long-term deflection monitoring for bridges using $\mathrm{X}$ and $\mathrm{C}$-band time-series SAR interferometry". Remote Sens 2019;11(11):1258. 715 
[38] Gagliardi V., Tosti F., Bianchini Ciampoli L., D'Amico F., Alani A. M., Battagliere M. L., and Benedetto A. "Monitoring of bridges by MTInSAR and unsupervised machine learning clustering techniques", Proc. SPIE 11863, Earth Resources and Environmental Remote Sensing/GIS Applications XII, 118630I (12 September 2021); https://doi.org/10.1117/12.2597509

[39] Joshaghani, A., Identifying the problematic areas with structura deficiencies of pavements using non-destructive tests (NDT), International Journal of Pavement Engineering, 20(11), 1359-1369, 2019

[40] Plati, C., Loizos, A., Gkyrtis, K., Integration of non-destructive testing methods to assess asphalt pavement thickness, NDT and E International, 115,102292, 2020

[41] Capozzoli, L., Rizzo, E., Combined NDT techniques in civil engineering applications: Laboratory and real test, Construction and Building Materials, 154(15), 1139-1150, 2017

[42] Plati, C., Loizos, A., Using ground-penetrating radar for assessing the structural needs of asphalt pavements, NDT and E International, 27(3), 273-284, 2012

[43] Al-Qadi, I.L., Zhao, S., Shangguan, P., Railway ballast fouling detection using GPR data: Introducing a combined time-frequency and discrete wavelet techniques, Near Surface Geophysics, 14(2), 145-153, 2016

[44] Bianchini Ciampoli L., Tosti F., Brancadoro M.G., D'Amico F., Alani A.M. and Benedetto, A. A spectral analysis of ground-penetrating radar data for the assessment of the railway ballast geometric properties, NDT \& E International, 90, 39-47, 2017

[45] Gopalakrishnan, K., Thompson, M.R., Use of nondestructive tes deflection data for predicting airport pavement performance, Journal of Transportation Engineering, 133(6), 389-395, 2007

[46] Benedetto, A., Tosti, F. Inferring bearing ratio of unbound materials from dielectric properties using GPR: The case of runaway safety areas (2013) Airfield and Highway Pavement 2013: Sustainable and Efficient Pavements - In: Proceedings of the 2013 Airfield and Highway Pavement Conference, pp. 1336-1347. DOI: 10.1061/9780784413005.113

[47] Nasimifar, M., Thyagarajan, S., Chaudhari, S., Sivaneswaran, N., Pavement Structural Capacity from Traffic Speed Deflectometer for Network Level Pavement Management System Application, Transportation Research Record, 2673(2), 456-465, 2019

[48] Tosti, F., Bianchini Ciampoli, L., D'Amico, F., Alani, A.M., Benedetto, A., An experimental-based model for the assessment of the mechanical properties of road pavements using ground-penetrating radar, Construction and Building Materials, 165, 966-974, 2018

[49] U.S. Department of Transportation Federal Aviation Administration (FAA), Advisory Circular 150/5320-6F, Airport Pavement Design and Evaluation, 2016

[50] American Association of State Highway and Transportation Officials (AASHTO), Guidelines for Geometric Design of Low-Volume Road, Ed. AASHTO, Washington, USA, 2019

[51] Tosti, F., Adabi, S., Pajewski, L., Schettini, G., Benedetto, A. Largescale analysis of dielectric and mechanical properties of pavement using GPR and LFWD (2014) Proceedings of the 15th International Conference on Ground Penetrating Radar, GPR 2014, art. no. 6970551, pp. 868-873.

[52] Menghini L., Bella F., Sansonetti G., and Gagliardi V. "Evaluation of road pavement conditions by Deep Neural Networks (DNN): an experimental application", Proc. SPIE 11863, Earth Resources and
Environmental Remote Sensing/GIS Applications XII, 118630N (12 September 2021); https://doi.org/10.1117/12.2599894

[53] A. Benedetto et al., "A simulation-based approach for railway applications using GPR," 2016 16th International Conference on Ground Penetrating Radar (GPR), 2016, pp. 1-6, doi: 10.1109/ICGPR.2016.7572609.

[54] Bonano M., Manunta M., Pepe A., Paglia L. and Lanari R., "From Previous C-Band to New X-Band SAR Systems: Assessment of the DInSAR Mapping Improvement for Deformation Time-Series Retrieval in Urban Areas," in IEEE Transactions on Geoscience and Remote Sensing, vol. 51, no. 4, pp. 1973-1984, April 2013, doi: 10.1109/TGRS.2012.2232933

[55] Alani A. M., Tosti F., Bianchini Ciampoli L., Gagliardi V., Benedetto A., (2020). "An integrated investigative approach in health monitoring of masonry arch bridges using GPR and InSAR technologies". NDT \& E International, 102288. https://doi.org/10.1016/j.ndteint.2020.102288

[56] Alani AM, Tosti F, Banks K, Bianchini Ciampoli L, Benedetto A. Nondestructive assessment of a historic masonry arch bridge using ground penetrating radar and 3D laser scanner. In: Proceedings of the IMEKO international conference on metrology for archaeology and cultural heritage (METROARCHAEO2017). Lecce, Italy; Oct 2017

[57] Tosti F., Gagliardi V., D'Amico F., Alani A.M., "Transport infrastructure monitoring by data fusion of GPR and SAR imagery information".Transp Res Proc 2020; 45:771-778. 721. https://doi.org/10.1016/j.trpro.2020.02.097

[58] D'Amico F., Gagliardi V., Bianchini Ciampoli L., Tosti F., "Integration of InSAR and GPR Techniques for Monitoring Transition Areas in Railway Bridges”. NDT\&E International, 115, 102291, 2020 https://doi.org/10.1016/j.ndteint.2020.102291

[59] Gagliardi, V.; Bianchini Ciampoli, L.; Trevisani, S.; D’Amico, F.; Alani, A.M.; Benedetto, A.; Tosti, F. "Testing Sentinel-1 SAR Interferometry Data for Airport Runway Monitoring: A Geostatistical Analysis". Sensors 2021, 21, 5769. https://doi.org/10.3390/s21175769

[60] Bianchini Ciampoli L., Gagliardi V., Ferrante C., Calvi A., D’Amico F., Tosti F., "Displacement Monitoring in Airport Runways by Persistent Scatterers SAR Interferometry". Remote Sens. (2020), 12, 3564. https://doi.org/10.3390/rs12213564

[61] Gagliardi V., Bianchini Ciampoli L., D'Amico F., Tosti F., Alani A. and Benedetto A. "A Novel Geo-Statistical Approach for Transport Infrastructure Network Monitoring by Persistent Scatterer Interferometry (PSI)". In: 2020 IEEE Radar Conference, Florence, Italy, 2020, pp. 1-6, doi: 10.1109/RadarConf2043947.2020.9266336

[62] Bianchini Ciampoli L., Gagliardi V., Calvi A., D’Amico F., Tosti F. "Automatic network-level bridge monitoring by integration of InSAR and GIS catalogues". Proceedings of SPIE 2019. https://doi.org/10.1117/12.2527299

[63] Biscarini C., Catapano I., Cavalagli N., Ludeno G., Pepe F.A., Ubertini F. "UAV photogrammetry, infrared thermography and GPR for enhancing structural and material degradation evaluation of the Roman masonry bridge of Ponte Lucano in Italy", NDT \& E International, 115, 2020, 102287

[64] Gagliardi V., Bianchini Ciampoli L., D’Amico F., Alani A. M., Tosti F., Benedetto A., "Multi-Temporal SAR Interferometry for Structural Assessment of Bridges: The Rochester Bridge Case Study". International Airfield and Highway Pavements Conference 202. https://ascelibrary.org/doi/abs/10.1061/9780784483510.028 